\title{
An Efficient Method for Qualitative Screening of Ligninolytic Enzyme Potential of Ganoderma lucidum
}

\author{
Harsimran Kaur, S. Kapoor and Shivani Sharma* \\ Department of Microbiology, Punjab Agricultural University, Ludhiana-141004, \\ Punjab, India \\ *Corresponding author
}

\begin{tabular}{|l|}
\hline Ke y w o r d s \\
$\begin{array}{l}\text { ABTS, Ganoderma } \\
\text { lucidum, Guaiacol, } \\
\text { Ligninolytic, RBBR }\end{array}$ \\
\hline Article Info \\
\hline $\begin{array}{l}\text { Accepted: } \\
\text { 12 July 2018 } \\
\text { Available Online: } \\
\text { 10 August } 2018\end{array}$ \\
\hline
\end{tabular}

\section{A B S T R A C T}

This research aimed to evaluate the potential screening of different strains of white rot fungi Ganoderma lucidum to produce different ligninolytic enzymes which play an important role in transformation and mineralization of various organic pollutants, production of commercially valuable biobased products delignify paper, animal feed and biofuel production. The qualitative screening is a crucial step in isolation and selection of potential lignolytic fungi. Four strains of Ganoderma lucidum, a well-known medicinal fungus, were used to quantify the qualitative screening process for their ligninolytic activities by using different concentrations of three chromogenic indicators viz., ABTS, guaiacol and RBBR. Among the three tested indicators, $0.08 \%$ ABTS concentration gave better visual expressions for ligninolytic activities of the fungal strains, followed by 0.075 $\%$ guaiacol. GL-1 and GL-2 strains were found to be hyper-ligninolytic strains with higher potency index values and higher tolerance capabilities towards the chromogenic indicator compounds; whereas GL-3 and GL-4 strains were grouped as hypo-ligninolytic strains due to their low potency index values. These strains with higher ligninolytic activities can be considered as potential candidates for development of an efficient biological system for the treatment of textile industry wastewaters and bioremediation of polluted ecosystems.

\section{Introduction}

Lignin is a naturally occurring highly recalcitrant substance present in lignocellulosic biomasses. The extensive polymerization, hydrophobic and impermeability properties impart towards resistance of lignin for both chemical and biological degradations; hence it acts as a barrier against microbial and pest attacks, oxidative stress and mechanical pressure during plant protection (Sanchez 2009). In spite of this, few microbial populations are able to degrade lignin to carbon dioxide due to their robust enzyme systems (Kersten and Cullen 2007).

White rot fungi (WRF) possess a unique enzymatic system for lignin degradation and mineralize the polymer among other ligninolytic microbes. Therefore, broad substrate specificity and catalytic properties of WRF has been considered as a biological alternative for chemical oxidative processes in the transformation and mineralization of lignin 
related compounds such as Persistent Organic Pollutants (POPs) such as industrial dyes, chlorophenols, polychlorinated biphenyls, polycyclic aromatic hydrocarbons (PAHs), pesticides (Rodríguez-Couto 2009; Lanfermann et al., 2015). This WRF secrete nonspecific hydrolytic and oxidative ligninolytic enzymes namely laccases (EC 1.10. 3.2), manganese peroxidase (MnPs, EC 1.11.1.13), lignin peroxidases (LiPs, EC 1.11.10.14) and versatile peroxidases (VPLs, EC 1.11.1.16) (Janusz et al., 2013; RiveraHoyos et al., 2015). These enzymes catalyze the oxidation of various phenolic and nonphenolic compounds and complementarily reducing the molecular oxygen to water (Casciello et al., 2017). The enzymes from wood-rotting basidiomycetes possess significant interest because of their ability to utilize a wide spectrum of carbon sources, including intermediates of lignin degradation, phenols, and heterocyclic compounds (Shrestha et al., 2016).

The isolation and identification of white-rot fungi for its ligninolytic capabilities through screening process plays a vital role in exploiting its potential in numerous environmental and biotechnological applications such as bioremediation of industrial wastewater and contaminated sites (Lee et al., 2006; Brock et al., 2009). The primary screening for ligninolytic potential are usually carried out with chromogenic indicators, based on the fact that these compounds make rapid screenings possible due to appearance of reliable visual expressions of enzyme positives on the indicator incorporated agar plates via actions of ligninolytic enzymes on these compounds without any elaborated measurements. This confirmation is supposed to be a baseline for production of lignin modifying enzymes before their optimization and application (Wunch et al., 1997; Alfarra et al., 2013).

The commonly used indicator pointers are guaiacol, 2,2'-azino-bis ethylbenzthiazoline-6-sulphonic (ABTS), syringaldazine, tannic acid, Azure B, Remazol Brilliant Blue-R (RBBR), 2,4dichlorophenol (2,4-DCP) (Coll 1993; D'Souza et al., 1999; Floch et al., 2007; Alfarra et al., 2013; Casciello et al., 2017). Positive results have been experiential through the different variations which came into view on the diverse solid medium. The curving of ABTS colorless agar media into colored surface ranging from pale green to dark purplish brown indicates a positive result; while Azure B blue agar media should give a negative result to confirm the presence of laccase activity. The appearance of reddish brown colored zones around or below the fungal colony on guaiacol or tannic acid agar media is a good proof of ligninolytic enzyme activities of fungi (Alfarra et al., 2013). The pale yellow syringaldazine gets oxidized to purple colored compound in the present of laccase, whereas the combined action of peroxidases and hydrogen peroxide-producing oxidases decolorizes the blue color of RBBR dye (Keyser et al., 1978; Mtui and Masalu 2008).

Most of the studies are based on screening interpret either presence or absence of ligninolytic enzymes in certain fungi (Kiiskinen et al., 2004; Mtui and Masalu 2008), with very few reports correlating fungal growth to ligninolytic production potentials of fungi (Keyser et al., 1978; Teck et al., 2011). There is a close relationship between the growth and ligninolytic potentials of fungi, which could be easily derived from the potency index values obtained from the ratio of activity halo area and fungal colony against incubation period. Higher potency index values signifies higher ligninolytic enzyme activities and vice versa (Teck et al., 2011). During an industrial process, a fungus with higher ligninolytic enzyme production rates with least growth in biomass is desirable 
in order to avoid addition cost and difficulties during enzyme recovery and purification steps (Uhlig 1998). Hence, a proper screening process for selection of a highly potent ligninolytic fungus is a crucial step.

Most of the studies have been focused on Phanerochaete chrysosporium, followed by Trametes versicolor, Bjerkandera adusta and Pleurotus sp. (Da Silva Coelho-Moreira et al., 2013). Thus, there is a need to screen more robust ligninolytic enzyme producing fungi. In the present study, four strains of G. lucidum, a well-known medicinal white rot fungus, were screened for their ligninolytic potentials on the basis of radial growth rates and potency index values by using ABTS, Guaiacol and RBBR as screening reagents at different concentration rates. A correlation between the effects of variable concentration rates of each screening agent incorporated agar media on fungal growth rate as well as potency index value was derived. The present investigation also revealed that the fruiting strains of Ganoderma lucidum (GL-1, GL-2) possess higher ligninolytic activity in comparison to non-fruiting strains (GL-3, GL-4).

\section{Materials and Methods}

\section{Mushroom strains}

The four strains of Ganoderma lucidum namely GL-1, GL-2, GL-3, GL-4 procured from the germplasm collection of edible mushrooms, Directorate of Mushroom Research, Solan, India.

\section{Culture media used}

Potato Dextrose Agar (PDA) medium composed of $(\mathrm{g} / \mathrm{l})$ : peeled potatoes 200, dextrose 20 and agar 15 were used to maintain stock cultures as well as to prepare inoculum cultures. Rice bran medium and modifiedLME medium were used for qualitative and quantitative screening of ligninolytic potentials of the fungal cultures. The rice bran agar medium was composed of $(\mathrm{g} / \mathrm{l})$ : yeast extract 4.0, $\mathrm{MgSO}_{4}$ 0.5, $\mathrm{KH}_{2} \mathrm{PO}_{4} 2.0, \mathrm{~K}_{2} \mathrm{HPO}_{4}$ 2.3 , citric acid 0.57 , glucose 1.0 , rice bran 15.0, agar-agar 20.0. The composition of modified-LME agar medium (g/l) was: ammonium oxalate $0.25, \quad \mathrm{KH}_{2} \mathrm{PO}_{4} \quad 1.0$, $\mathrm{K}_{2} \mathrm{HPO}_{4} \quad 1.0, \mathrm{MgSO}_{4} \cdot \mathrm{H}_{2} \mathrm{O} \quad 0.5, \mathrm{CaCl}_{2} \cdot 2 \mathrm{H}_{2} \mathrm{O}$ $0.01, \mathrm{CuSO}_{4} .5 \mathrm{H}_{2} \mathrm{O} 0.01, \mathrm{MnSO}_{4} 0.01$, tartaric acid 0.5, yeast extract 0.01 and agar-agar 20.0. After incorporation of chromogenic indicators to the media containing flasks, the media were autoclaved at $121^{\circ} \mathrm{C}$ for 20 minutes.

\section{Chromogenic indicators used}

Three different chromogenic indicator viz. 2, 2-Azinobis-3-ethylbenzthiazoline -6sulphonate (ABTS) (Sigma-Aldrich), Omethoxy phenol (Guaiacol) (HiMedia) and Remazol brilliant blue-R (RBBR) (SigmaAldrich) were added individually at different concentrations to the solid media before autoclaving in order to quantify the qualitative screening process for ligninolytic potentials of white-rot fungi (Table 1).

Rice bran agar medium was used for ABTS and Guaiacol additions, whereas in modifiedLME agar plates were incorporated with RBBR to prevent the possible dye adsorption effect of rice bran.

\section{Culture conditions used}

The chromogenic indicator containing agar plates were inoculated individually with one $10 \mathrm{~mm}$ agar plug of 5 days old mycelium of each strain. The inoculated plates were incubated at $30^{\circ} \mathrm{C}$ in the dark for the period of 8 days and observed each day for the growth of the fungal mycelium as well as for the clearance /appearance of color zones, under or around the fungal colonies.

Selection criteria used 
The selection criteria were based on the appearance of a positive reaction and capabilities of the fungus to grow at different concentrations of chromogenic indicators supplemented in agar plates (Table 1). The potency index (PI) values were calculated, to find out the hyper and hypo secretors of ligninolytic enzymes, by using the following formula (Teck et al., 2011):

Area of clearance or color zone $\left(\mathrm{mm}^{2}\right)$ Potency Index $(\mathrm{PI})=$

$$
\text { Area of colony }\left(\mathrm{mm}^{2}\right)
$$

\section{Statistical Analysis}

The data obtained for radial growth and expected color zone for different strains and different concentration rates of chromogenic indicator compounds was statistically analyzed through ANOVA (CRD) to see the critical difference at 5\% level of significance using CPCS1 Software.

\section{Results and Discussion}

\section{Effect on growth patterns}

On the positive control plates (inoculated agar plates without chromogenic indicator compounds), the growth rates of all the four strains of $G$. lucidum were affected by the medium composition used. The radial growth rates were higher on rice bran agar plates than those on M-LME agar medium. On rice bran agar plates, the radial growth pattern obtained was as follows: GL-1 > GL-2 > GL-3 > GL-4 on $4^{\text {th }}$ day of incubation; whereas on M-LME agar plates, this pattern was: GL-3 > GL-4 > GL-2 > GL-1 (Tables 1A, 2A, 3A; Plate 1).

The radial growth rates of all the four strains were reduced with incorporation of chromogenic indicator compounds. The strain responses were variable towards different chromogenic compounds as well as their concentrations. However in general, ABTS incorporation was least suppressive, followed by $\mathrm{RBBR}$ and the presence of guaiacol in growth medium severely affected the radial growth rates of all the four strains. Though the higher concentrations of ABTS were highly inhibitory of radial growth rates, but their suppressive effects were reduced with increase in the incubation period in all strains. On the other hand, higher concentrations of guaiacol completely inhibited mycelial extension rates of all the four strains of G. lucidum. The individual strain responses towards RBBR incorporation in the growth medium were highly variable, and it was difficult to determine the exact effect of RBBR on the growth. The ABTS and guaiacol were less suppressive to GL-1 and GL-2 strains, but suppressive effect was more pronounced in case of GL-3 and GL-4 strains. However, RBBR incorporation gave a variable pattern of radial growth in G. lucidum strains. In $0.08 \%$ ABTS samples, the radial growth reduction pattern on $4^{\text {th }}$ day of incubation was as follows: $79.9 \%$ for GL-3 > 78.1\% for GL-4 > $72.3 \%$ for GL-1 > $64.4 \%$ for GL-2. The percent radial growth reduction obtained for GL-1, GL-2, GL-3 and GL-4 strains in $0.075 \%$ guaiacol on $4^{\text {th }}$ day of incubation were $56.5 \%>61.7 \%>60.6 \%>61.5 \%$, respectively.

\section{Effect on ligninolytic activity zone patterns}

During quantification studies, all the four strains showed positive responses for oxidation as well as discoloration activities when incubated at $30^{\circ} \mathrm{C}$ in dark for the incubation period of 8 days (Plate 1).

The purplish red color and reddish brown color zones were observed under or around the fungal colonies in ABTS and guaiacol incorporated agar plates, respectively; whereas in case of RBBR dye, there was appearance of 
a colorless halo under fungal colonies of all four strains of $G$. lucidum. These color changes were a strong indication for secretions of ligninolytic enzymes by these strains. Though all the four strains were ligninolytic positive, but the appearance of color changes with respect to incubation time as well as color intensity were highly variable among the four strains. In RBBR and guaiacol incorporated plates, the activity zones appeared within 24 hours of incubation for all the four strains. In case of ABTS, these zones were obtained in GL-1 and GL-2 strains within 24 hours, but GL-3 and GL-4 strains showed positive results after an incubation period of 72 hours. Moreover, GL-1 and GL-2 strains gave deeper color intensity or brighter clearance zones on the chromogenic indicator incorporated agar plates than GL-3 and GL-4 strains. With an increase in chromogenic indicator compound concentrations and incubation periods, the color zones produced by all the four strains were also gotten more intensified (Heatmap 1B, 2B, 3B).

The potency index values for all the three chromogenic indicators ranged widely for the selected strains of G. lucidum with respect to concentration and incubation period. On the basis of potency index values, the strains were divided into two groups for their ligninolytic potentials: hyper and hypo ligninolytic enzymes producer strains. GL-1 and GL-2 strains were found to have hyper production potentials (PIs $\geq 1.000$ ), however GL-3 and GL-4 strains showed low potency index values (PIs < 1.000) due to hypo ligninolytic potentials. In general, increasing concentrations of chromogenic indicators showed slight increases in potency index values, but on the daily basis observation there was no regular pattern of changes in potency index values (Fig. 1A, B, C).

The oxidation patterns of chromogenic compounds on agar plates strongly supported grouping of GL-1 and GL-2 strains as hyper and GL-3 and GL-4 strains as hypo ligninolytic enzymes producer on the basis of potency index values. The increasing concentrations of ABTS and RBBR though decreased their own oxidation rates but the obtained color zone intensities and potency index values were higher enough for using these concentrations in screening process for easy detection of ligninolytic positive white rot fungus. But on the other hand higher concentrations severely affected the guaiacol oxidation due to drastic reductions in fungal growth rates. On the $5^{\text {th }}$ day of incubation the obtained percent oxidation of ABTS of total plate area at $0.08 \%$ ABTS concentration levels was as follows: $50.57 \%$ for GL-2 > $37.80 \%$ for GL-1 > $4.61 \%$ for GL-3 $>2.66 \%$ for GL-4 (Fig. 2A).

Table.1 Chromogenic indicators used for quantification of ligninolytic potentials of G. lucidum strains

\begin{tabular}{|c|c|l|l|}
\hline $\begin{array}{c}\text { Sr. } \\
\text { No. }\end{array}$ & $\begin{array}{c}\text { Chromogenic } \\
\text { indicator }\end{array}$ & \multicolumn{1}{|c|}{ Expected indicator zone } & \multicolumn{1}{|c|}{ Percent Concentration (\%) } \\
\hline $\mathbf{1}$ & ABTS & $\begin{array}{l}\text { Appearance of green color } \\
\text { (Murugesan } \text { et al., 2007) }\end{array}$ & $0.02,0.04,0.06,0.08(\mathrm{w} / \mathrm{v})$ \\
\hline $\mathbf{2}$ & Guaiacol & $\begin{array}{l}\text { Appearance of reddish brown } \\
\text { color (López } \text { et al., 2006) }\end{array}$ & $0.075,0.150,0.225,0.300(\mathrm{v} / \mathrm{v})$ \\
\hline $\mathbf{3}$ & RBBR & $\begin{array}{l}\text { Clearance of blue color } \\
\text { (Murugesan } \text { et al., 2007) }\end{array}$ & $0.005,0.010,0.015,0.020(\mathrm{w} / \mathrm{v})$ \\
\hline
\end{tabular}


Table.1A Areas $\left(\mathrm{mm}^{2}\right)$ of fungal colonies of G. lucidum strains on agar plates supplemented with different concentrations of ABTS

\begin{tabular}{|c|c|c|c|c|c|c|c|c|c|}
\hline \multirow[t]{2}{*}{ Treatment } & \multirow[t]{2}{*}{ Strain } & \multicolumn{8}{|c|}{ Area of growth $\left(\mathrm{mm}^{2}\right)$} \\
\hline & & Day 1 & Day 2 & Day 3 & Day 4 & Day 5 & Day 6 & Day 7 & Day 8 \\
\hline \multirow[t]{4}{*}{$\mathrm{C}-0$} & GL-1 & 254.3 & 820.7 & 2403.5 & 4455 & 6264.6 & 6358.5 & 6358.5 & 6358.5 \\
\hline & GL-2 & 314 & 820.7 & 2149.9 & 4337.5 & 6358.5 & 6358.5 & 6358.5 & 6358.5 \\
\hline & GL-3 & 464.8 & 1017.4 & 2232.9 & 3920.1 & 6358.5 & 6358.5 & 6358.5 & 6358.5 \\
\hline & GL-4 & 391.5 & 980 & 2289.1 & 3594.3 & 5671.6 & 6358.5 & 6358.5 & 6358.5 \\
\hline \multirow[t]{4}{*}{ C-1 } & GL-1 & 168.9 & 403.3 & 961.6 & 1833.8 & 2985.2 & 3773.6 & 5583 & 6311.5 \\
\hline & GL-2 & 209.4 & 452.2 & 1055.4 & 1783.6 & 3182 & 4614.1 & 6171.5 & 6264.6 \\
\hline & GL-3 & 139.6 & 477.6 & 872.2 & 1451.5 & 2610.5 & 3920.1 & 4940.6 & 5583 \\
\hline & GL-4 & 139.6 & 427.4 & 943.4 & 1362.8 & 2205.1 & 3701.4 & 5066 & 5716.2 \\
\hline \multirow[t]{4}{*}{$\mathrm{C}-2$} & GL-1 & 146.6 & 403.3 & 837.7 & 1613.3 & 2640.7 & 3810 & 5066 & 6358.5 \\
\hline & GL-2 & 184.6 & 452.2 & 980 & 1859.2 & 2763.5 & 4337.5 & 5321.3 & 6358.5 \\
\hline & GL-3 & 113 & 379.9 & 770.7 & 1406.8 & 2610.5 & 3846.5 & 4857.9 & 6311.5 \\
\hline & GL-4 & 125.9 & 303.6 & 660.2 & 1235.2 & 1884.8 & 3282.7 & 4376.5 & 5896.2 \\
\hline \multirow[t]{4}{*}{$\mathrm{C}-3$} & GL-1 & 168.9 & 368.5 & 854.9 & 1542.9 & 2317.4 & 3350.7 & 4735.2 & 6358.5 \\
\hline & GL-2 & 153.9 & 391.5 & 889.8 & 1758.7 & 2701.8 & 3810 & 5108.1 & 6264.6 \\
\hline & GL-3 & 119.4 & 293.4 & 503.8 & 1153.5 & 2015.2 & 3017.5 & 4221.6 & 6033.1 \\
\hline & GL-4 & 89.3 & 184.6 & 427.4 & 943.4 & 1758.7 & 2177.4 & 3488.9 & 4221.6 \\
\hline \multirow[t]{4}{*}{$\mathrm{C}-4$} & GL-1 & 146.6 & 368.5 & 770.7 & 1235.2 & 2149.9 & 2857.5 & 4337.5 & 5364.5 \\
\hline & GL-2 & 161.3 & 391.5 & 754.4 & 1542.9 & 2550.5 & 3350.7 & 4982.2 & 5896.2 \\
\hline & GL-3 & 119.4 & 209.4 & 439.7 & 787.2 & 1429 & 2491.2 & 3523.9 & 4816.8 \\
\hline & GL-4 & 89.3 & 161.3 & 403.3 & 787.2 & 1451.5 & 2260.9 & 3248.9 & 4107.2 \\
\hline
\end{tabular}

$\mathbf{C D}(\mathbf{P} \leq \mathbf{5 \%}) \quad$ Treatment $=90.15$, Strain $=80.63$, Incubation period $=114.03$

Total plate area $=6358.5 \mathrm{~mm}^{2}$, Medium used: Rice bran agar, "Treatment: C-0 = Positive Control, C-1 = $0.02 \%(w / v), C-2=0.04 \%(w / v), C-3=0.06 \%(w / v)$ and $\mathrm{C}-4=0.08 \%(\mathrm{w} / \mathrm{v})$ of ABTS 
Heat Map.1B Areas $\left(\mathrm{mm}^{2}\right)$ of color zones for ABTS oxidation by G. lucidum strains on solid medium

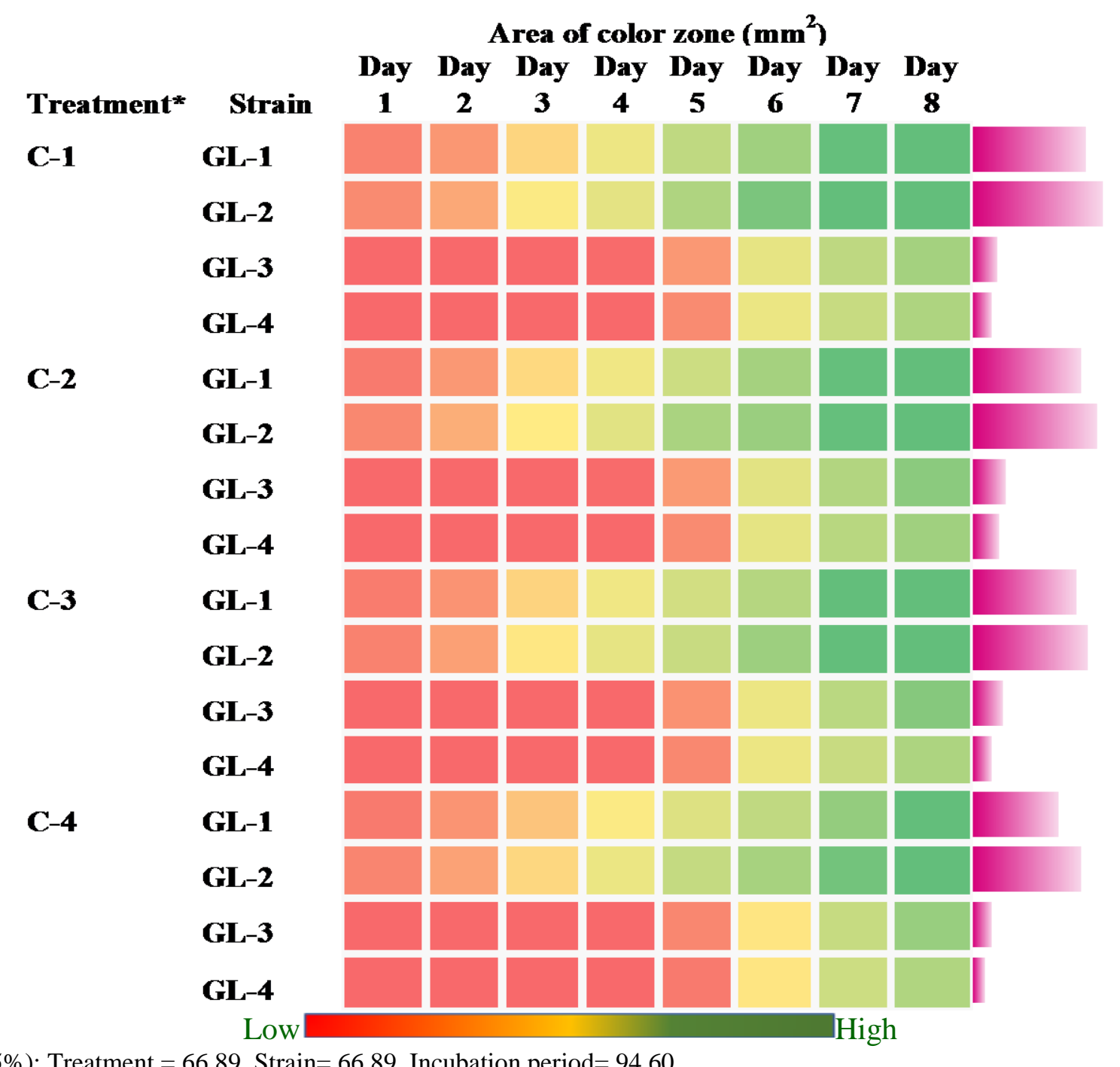

Critical Difference at $(\mathrm{P} \leq 5 \%)$ : Treatment $=66.89$, Strain $=66.89$, Incubation period $=94.60$

Total plate area $=6358.5 \mathrm{~mm}^{2}$, Medium used: Rice bran agar, "Treatment: C-1 $=0.02 \%(\mathrm{w} / \mathrm{v}), \mathrm{C}-2=0.04 \%(\mathrm{w} / \mathrm{v}), \mathrm{C}-3=0.06 \%(\mathrm{w} / \mathrm{v})$ and C-4 $=0.08 \%(\mathrm{w} / \mathrm{v})$ of ABTS 
Table.2A Areas $\left(\mathrm{mm}^{2}\right)$ of fungal colonies of G. lucidum strains on agar plates supplemented with different concentrations of Guaiacol

\begin{tabular}{|c|c|c|c|c|c|c|c|c|c|}
\hline \multirow[t]{2}{*}{ Treatment ${ }^{*}$} & \multirow[t]{2}{*}{ Strain } & \multicolumn{8}{|c|}{ Area of growth $\left(\mathrm{mm}^{2}\right)$} \\
\hline & & Day 1 & Day 2 & Day 3 & Day 4 & Day 5 & Day 6 & Day 7 & Day 8 \\
\hline \multirow[t]{4}{*}{$\mathrm{C}-\mathbf{0}$} & GL-1 & 254.3 & 820.7 & 2403.5 & 4455.0 & 6264.6 & 6358.5 & 6358.5 & 6358.5 \\
\hline & GL-2 & 314.0 & 820.7 & 2149.9 & 4337.5 & 6358.5 & 6358.5 & 6358.5 & 6358.5 \\
\hline & GL-3 & 464.8 & 1017.4 & 2232.9 & 3920.1 & 6358.5 & 6358.5 & 6358.5 & 6358.5 \\
\hline & GL-4 & 391.5 & 980.0 & 2289.1 & 3594.3 & 5671.6 & 6358.5 & 6358.5 & 6358.5 \\
\hline \multirow[t]{4}{*}{$\mathrm{C}-1$} & GL-1 & 89.3 & 168.9 & 722.3 & 1936.4 & 4298.7 & 5627.2 & 6311.5 & 6358.5 \\
\hline & GL-2 & 95.0 & 192.7 & 660.2 & 1661.1 & 3810.0 & 5987.3 & 6264.6 & 6358.5 \\
\hline & GL-3 & 139.6 & 346.2 & 872.2 & 1542.9 & 2889.1 & 5108.1 & 6358.5 & 6358.5 \\
\hline & GL-4 & 184.6 & 391.5 & 872.2 & 1384.7 & 2345.9 & 3957.2 & 5583.0 & 6358.5 \\
\hline \multirow[t]{4}{*}{ C-2 } & GL-1 & 78.5 & 78.5 & 78.5 & 78.5 & 78.5 & 78.5 & 78.5 & 78.5 \\
\hline & GL-2 & 78.5 & 78.5 & 78.5 & 78.5 & 78.5 & 78.5 & 78.5 & 78.5 \\
\hline & GL-3 & 78.5 & 78.5 & 78.5 & 78.5 & 78.5 & 78.5 & 78.5 & 78.5 \\
\hline & GL-4 & 78.5 & 78.5 & 78.5 & 78.5 & 78.5 & 78.5 & 78.5 & 78.5 \\
\hline \multirow[t]{4}{*}{ C-3 } & GL-1 & 78.5 & 78.5 & 78.5 & 78.5 & 78.5 & 78.5 & 78.5 & 78.5 \\
\hline & GL-2 & 78.5 & 78.5 & 78.5 & 78.5 & 78.5 & 78.5 & 78.5 & 78.5 \\
\hline & GL-3 & 78.5 & 78.5 & 78.5 & 78.5 & 78.5 & 78.5 & 78.5 & 78.5 \\
\hline & GL-4 & 78.5 & 78.5 & 78.5 & 78.5 & 78.5 & 78.5 & 78.5 & 78.5 \\
\hline \multirow[t]{4}{*}{$\mathrm{C}-4$} & GL-1 & 78.5 & 78.5 & 78.5 & 78.5 & 78.5 & 78.5 & 78.5 & 78.5 \\
\hline & GL-2 & 78.5 & 78.5 & 78.5 & 78.5 & 78.5 & 78.5 & 78.5 & 78.5 \\
\hline & GL-3 & 78.5 & 78.5 & 78.5 & 78.5 & 78.5 & 78.5 & 78.5 & 78.5 \\
\hline & GL-4 & 78.5 & 78.5 & 78.5 & 78.5 & 78.5 & 78.5 & 78.5 & 78.5 \\
\hline $\begin{array}{c}\mathrm{CD} \\
(\mathrm{P} \leq \mathbf{5} \%)\end{array}$ & \multicolumn{9}{|c|}{ Treatment $=31.87$, Strain $=28.51$, Incubation period $=34.91$} \\
\hline
\end{tabular}

Total plate area $=6358.5 \mathrm{~mm}^{2}$, Medium used: Rice bran agar, ${ }^{*}$ Treatment: C- $0=$ Positive Control, C-1 $=0.075 \%(\mathrm{v} / \mathrm{v}), \mathrm{C}-2=0.150 \%$ (v/v), C-3 = $0.225 \%$ $(\mathrm{v} / \mathrm{v})$ and $\mathrm{C}-4=0.300 \%(\mathrm{v} / \mathrm{v})$ of guaiacol 
Heat Map.2B Areas $\left(\mathrm{mm}^{2}\right)$ of color zones for Guaiacol oxidation by G. lucidum strains on solid medium

\section{Area of color zone $\left(\mathbf{m m}^{2}\right)$}

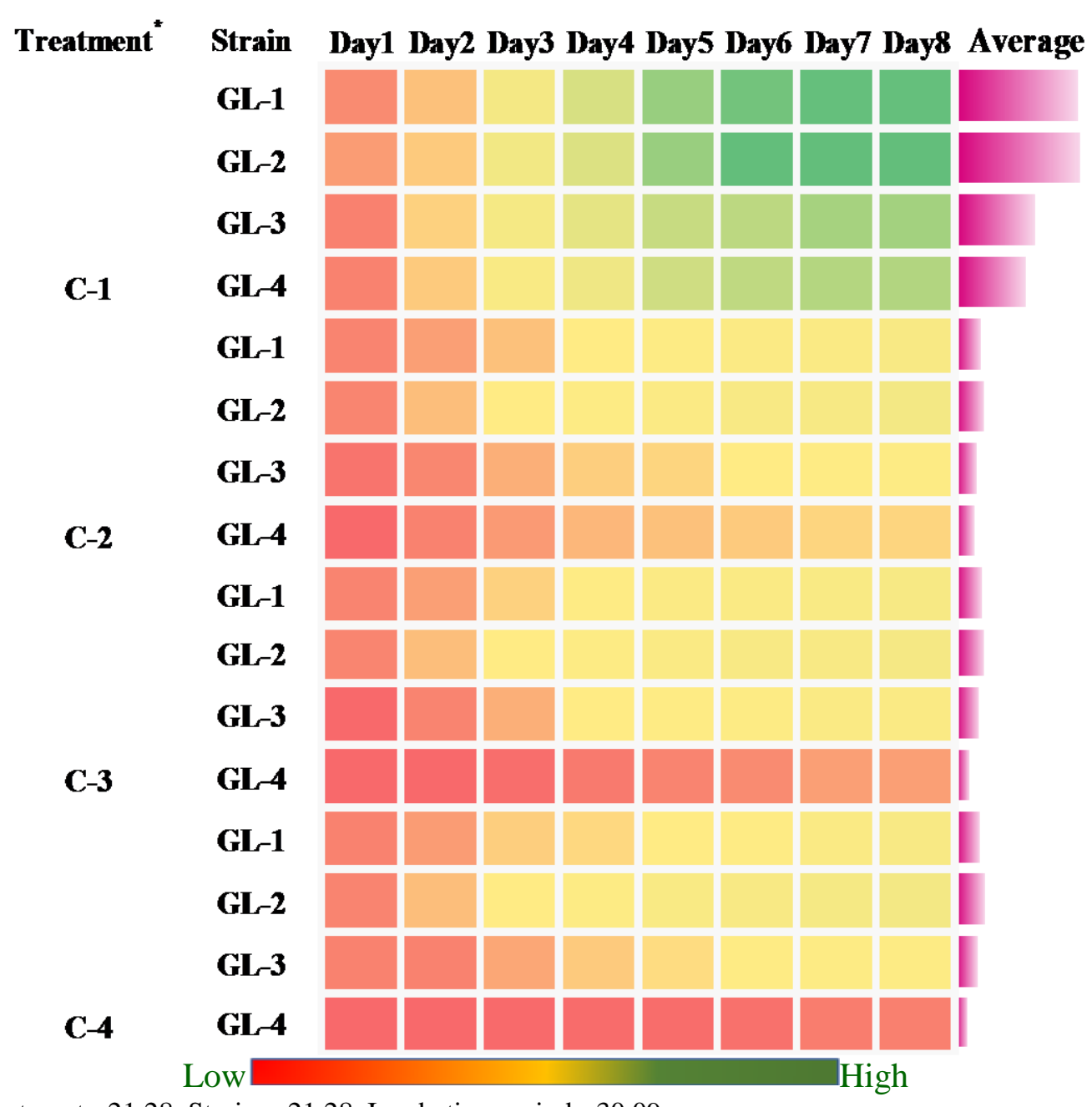

Critical Difference at $(\mathrm{P} \leq 5 \%)$ : Treatment $=21.28$, Strain $=21.28$, Incubation period $=30.09$

Total plate area $=6358.5 \mathrm{~mm}^{2}$, Medium used: Rice bran agar, "Treatment: $\mathrm{C}-1=0.075 \%(\mathrm{v} / \mathrm{v}), \mathrm{C}-2=0.150 \%(\mathrm{v} / \mathrm{v}), \mathrm{C}-3=0.225 \%(\mathrm{v} / \mathrm{v})$ and $\mathrm{C}-4=0.300 \%$ $(\mathrm{v} / \mathrm{v})$ of guaiacol 
Table.3A Areas $\left(\mathrm{mm}^{2}\right)$ of fungal colonies of G. lucidum strains on agar plates supplemented with different concentrations of RBBR

\begin{tabular}{|c|c|c|c|c|c|c|c|c|c|}
\hline \multirow[t]{2}{*}{ Treatment } & \multirow[t]{2}{*}{ Strain } & \multicolumn{8}{|c|}{ Area of growth $\left(\mathrm{mm}^{2}\right)$} \\
\hline & & Day 1 & Day 2 & Day 3 & Day 4 & Day 5 & Day 6 & Day 7 & Day 8 \\
\hline \multirow[t]{4}{*}{ C-0 } & GL-1 & 83.8 & 293.4 & 690.9 & 872.2 & 2149.9 & 2921.0 & 3385.0 & 4415.6 \\
\hline & GL-2 & 89.3 & 324.6 & 690.9 & 1036.3 & 2177.4 & 2857.5 & 3419.5 & 4494.5 \\
\hline & GL-3 & 95.0 & 368.5 & 738.2 & 1319.6 & 2432.5 & 3282.7 & 4415.6 & 5321.3 \\
\hline & GL-4 & 89.3 & 415.3 & 770.7 & 1298.2 & 2550.5 & 3350.7 & 4376.5 & 5495.1 \\
\hline \multirow[t]{4}{*}{ C-1 } & GL-1 & 106.8 & 273.5 & 530.7 & 907.5 & 2015.2 & 2640.7 & 3148.7 & 3810.0 \\
\hline & GL-2 & 106.8 & 263.8 & 630.2 & 1036.3 & 1988.8 & 2763.5 & 3248.9 & 3994.4 \\
\hline & GL-3 & 106.8 & 357.3 & 722.3 & 1194.0 & 2374.6 & 3282.7 & 4376.5 & 4940.6 \\
\hline & GL-4 & 106.8 & 391.5 & 738.2 & 1214.5 & 2432.5 & 3316.6 & 4376.5 & 4899.2 \\
\hline \multirow[t]{4}{*}{$\mathrm{C}-2$} & GL-1 & 106.8 & 254.3 & 517.1 & 1133.5 & 2068.6 & 2640.7 & 3282.7 & 4145.1 \\
\hline & GL-2 & 106.8 & 263.8 & 558.2 & 1133.5 & 2068.6 & 2550.5 & 3215.4 & 4183.3 \\
\hline & GL-3 & 106.8 & 346.2 & 630.2 & 1133.5 & 2403.5 & 3248.9 & 4183.3 & 4899.2 \\
\hline & GL-4 & 106.8 & 368.5 & 690.9 & 1153.5 & 2432.5 & 3385.0 & 4337.5 & 4899.2 \\
\hline \multirow[t]{4}{*}{$\mathrm{C}-3$} & GL-1 & 106.8 & 218.1 & 490.6 & 1194.0 & 2068.6 & 2317.4 & 3282.7 & 4069.4 \\
\hline & GL-2 & 106.8 & 235.8 & 600.9 & 1256.0 & 2149.9 & 2491.2 & 3215.4 & 3957.2 \\
\hline & GL-3 & 106.8 & 314.0 & 615.4 & 1341.1 & 2432.5 & 3316.6 & 4183.3 & 5024.0 \\
\hline & GL-4 & 106.8 & 324.6 & 630.2 & 1406.8 & 2491.2 & 3350.7 & 4455.0 & 5108.1 \\
\hline \multirow[t]{4}{*}{$\mathrm{C}-4$} & GL-1 & 106.8 & 201.0 & 572.3 & 1235.2 & 2068.6 & 2671.2 & 2953.0 & 3773.6 \\
\hline & GL-2 & 106.8 & 218.1 & 586.5 & 1298.2 & 2122.6 & 2953.0 & 3115.7 & 3846.5 \\
\hline & GL-3 & 106.8 & 283.4 & 615.4 & 1384.7 & 2260.9 & 3050.1 & 4337.5 & 5024.0 \\
\hline & GL-4 & 106.8 & 314.0 & 630.2 & 1429.0 & 2289.1 & 3282.7 & 4455.0 & 5321.3 \\
\hline
\end{tabular}

$\mathrm{CD}(\mathrm{P} \leq 5 \%) \quad$ Treatment $=36.53$, Strain $=32.68$, Incubation period $=46.21$

Total plate area $=6358.5 \mathrm{~mm}^{2}$, Medium used: M-LME, ${ }^{*}$ Treatment: C-0 $=$ Positive control, C-1 $=0.005 \%(\mathrm{w} / \mathrm{v}), \mathrm{C}-2=0.010 \%(\mathrm{w} / \mathrm{v}), \mathrm{C}-3=0.015 \%(\mathrm{w} / \mathrm{v})$ and $\mathrm{C}-4=0.020 \%(\mathrm{w} / \mathrm{v})$ of RBBR dye 
Heat Map.3B Areas $\left(\mathrm{mm}^{2}\right)$ of color zones for RBBR decolorization by G. lucidum strains on solid medium

Area of color zone ( $\left.\mathrm{mm}^{\mathrm{z}}\right)$

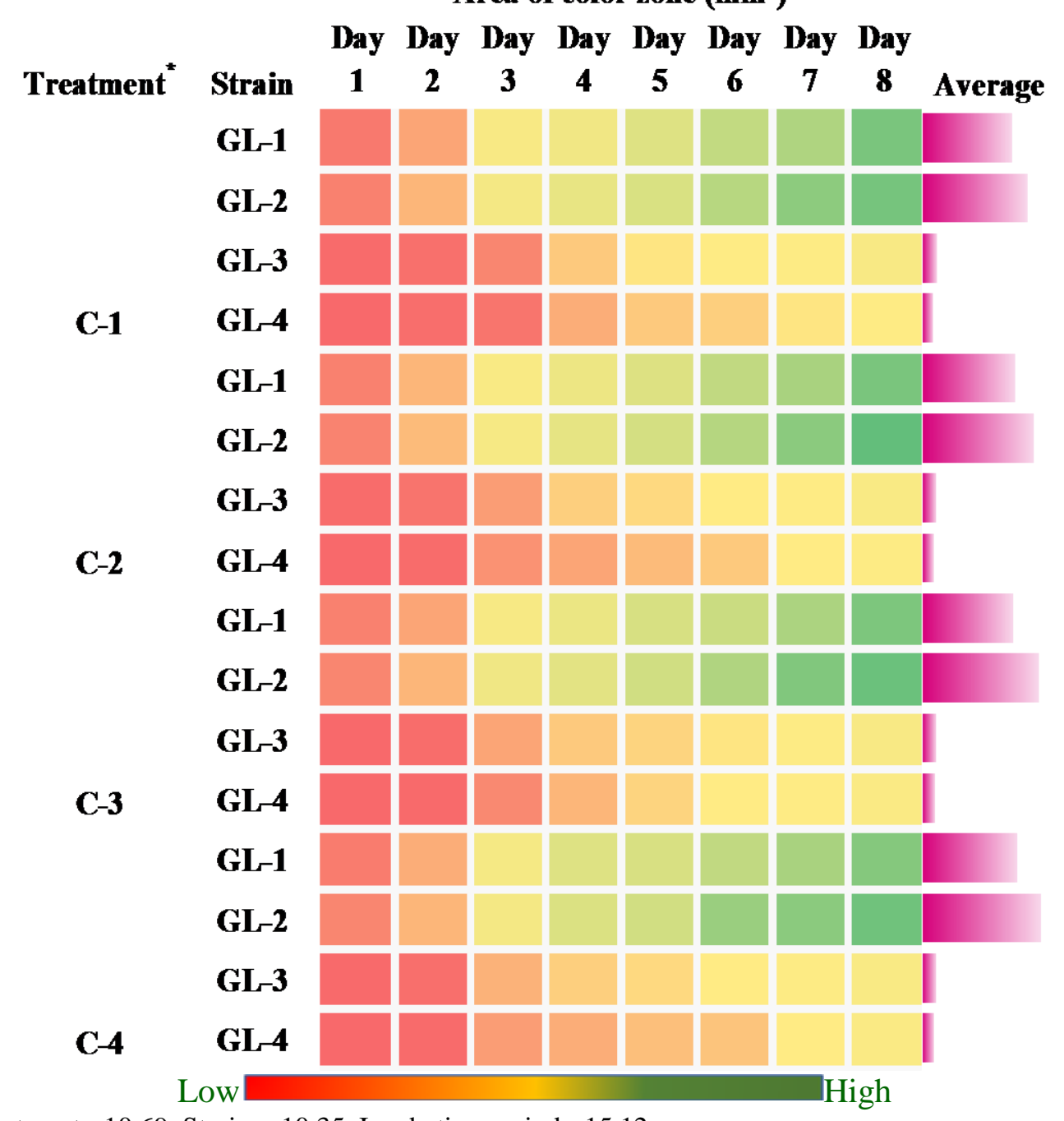

Critical Difference at $(\mathrm{P} \leq 5 \%)$ : Treatment $=10.69$, Strain $=10.35$, Incubation period $=15.12$

Total plate area $=6358.5 \mathrm{~mm}^{2}$, Medium used: M-LME, ${ }^{*}$ Treatment: C-0 $=$ Positive control, C-1 $=0.005 \%(\mathrm{w} / \mathrm{v}), \mathrm{C}-2=0.010 \%(\mathrm{w} / \mathrm{v}), \mathrm{C}-3=0.015 \%(\mathrm{w} / \mathrm{v})$ and $\mathrm{C}-4=0.020 \%(\mathrm{w} / \mathrm{v})$ of RBBR dye 
Fig.1 Effect of variable concentrations of different chromogenic indicators on potency index values for their oxidation by G. lucidum strains
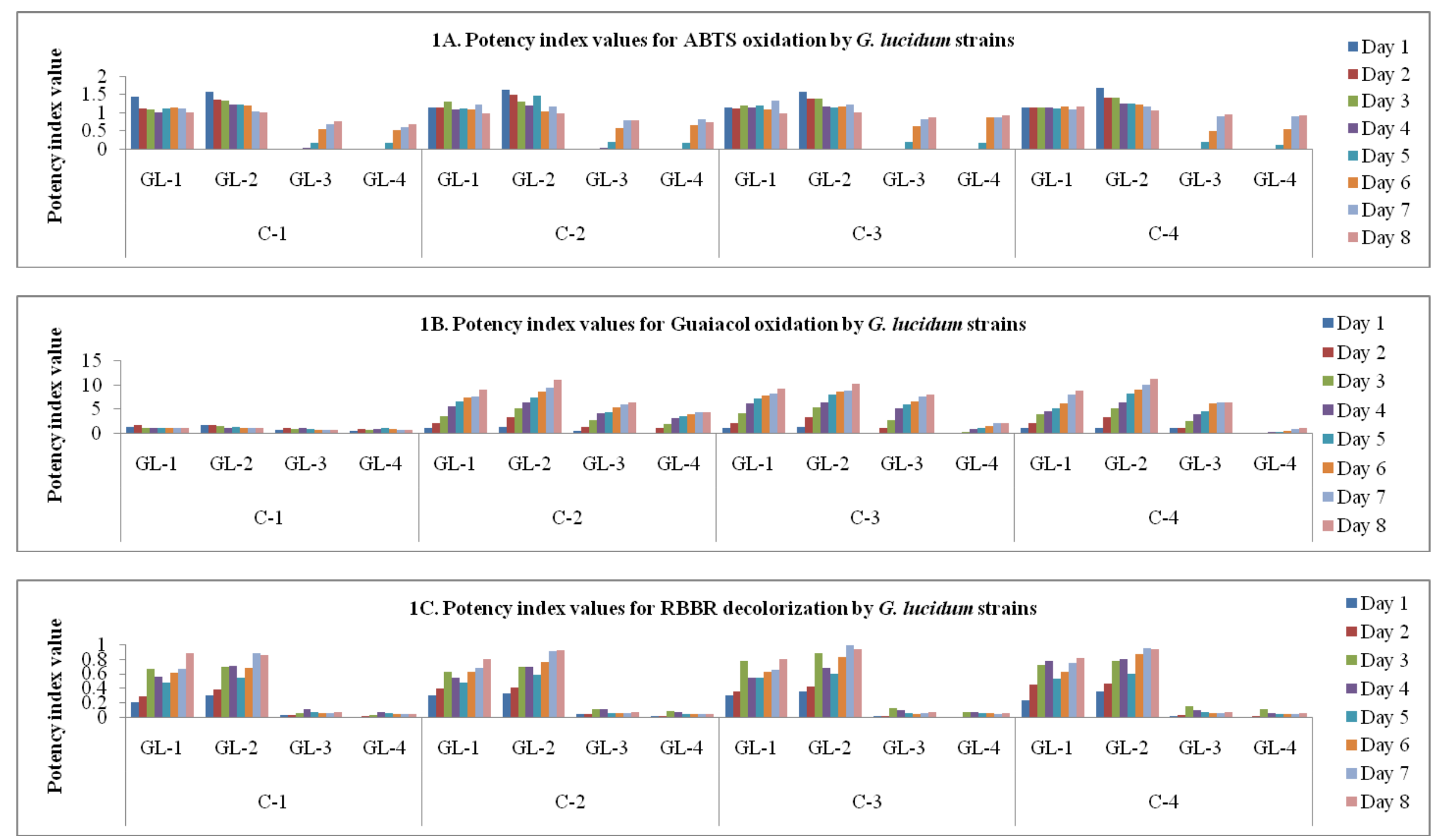
Fig.2 Effect of variable concentrations of different chromogenic indicators on their oxidation by G. lucidum strains
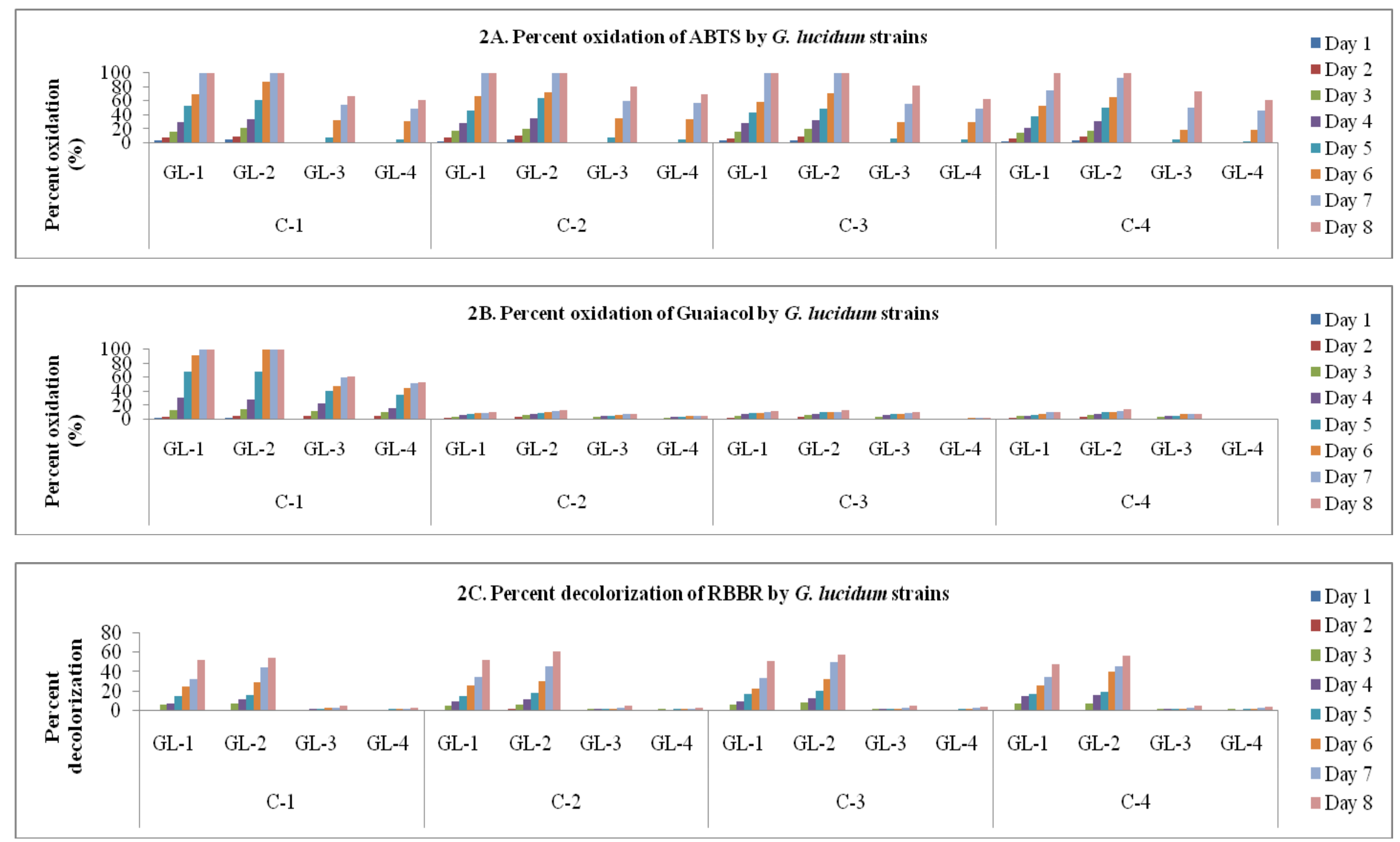
Plate.1 Quantification of qualitative assay on the agar plates incorporated with chromogenic compounds

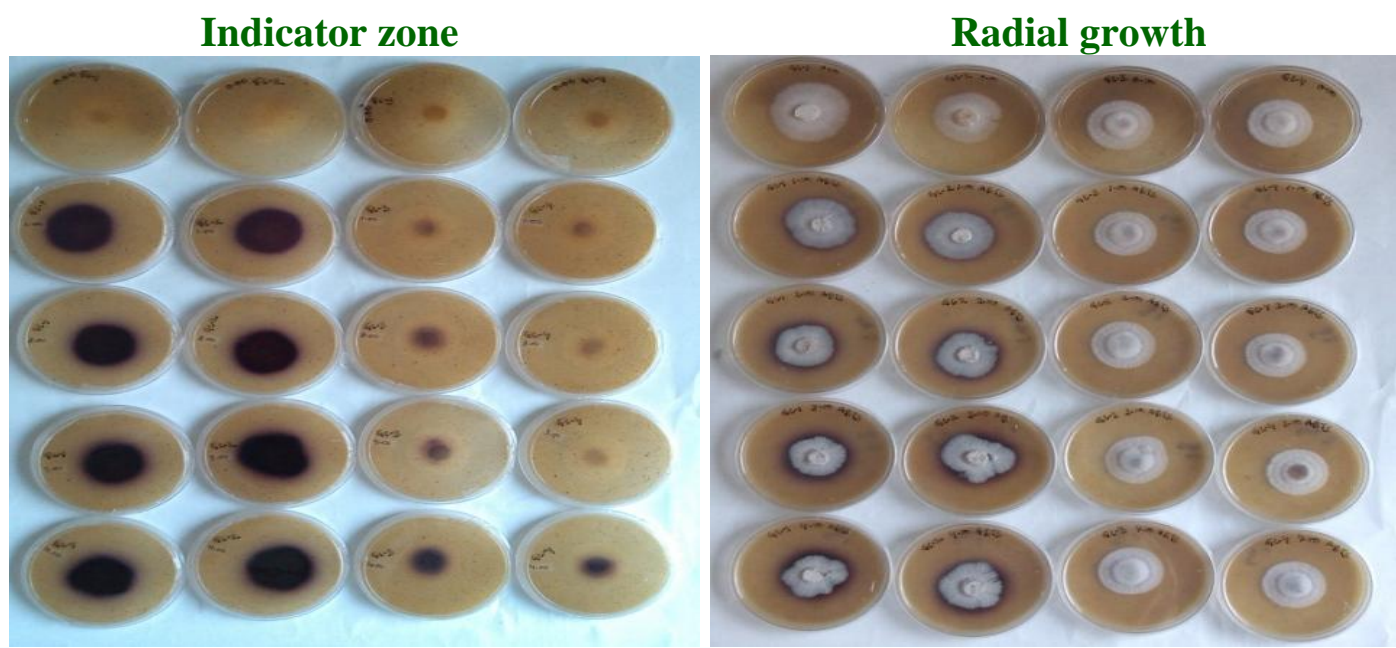

\section{A. ABTS incorporated agar plates}

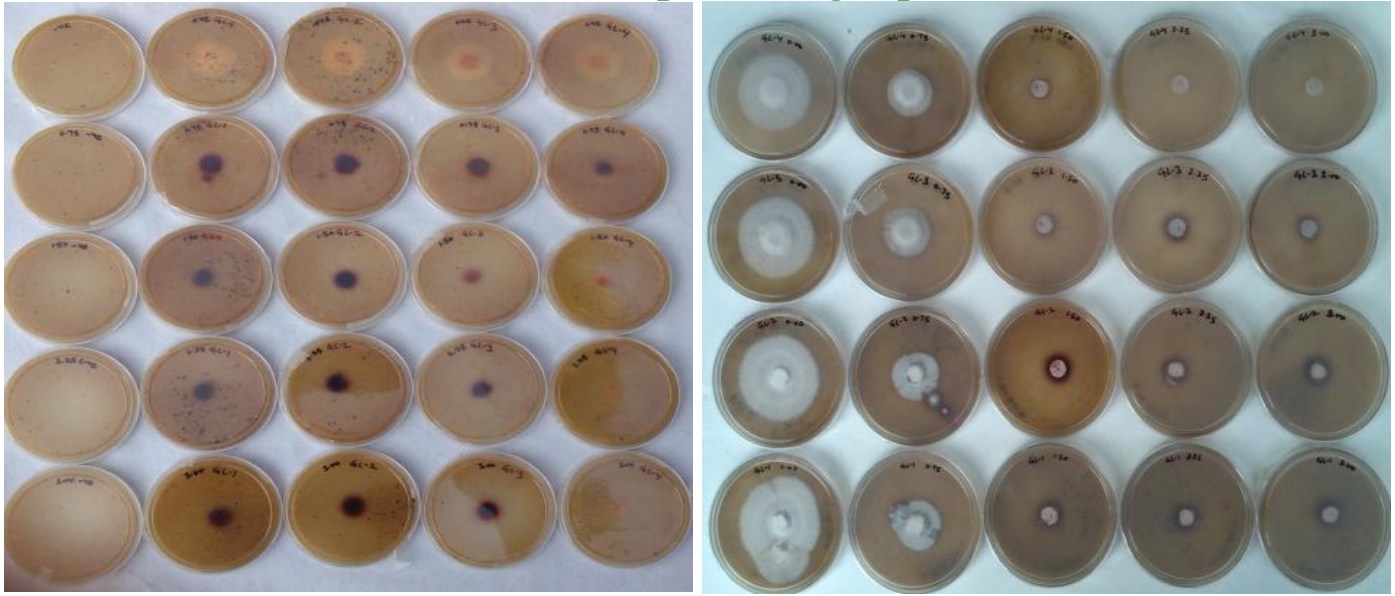

\section{B. Guaiacol incorporated agar plates}

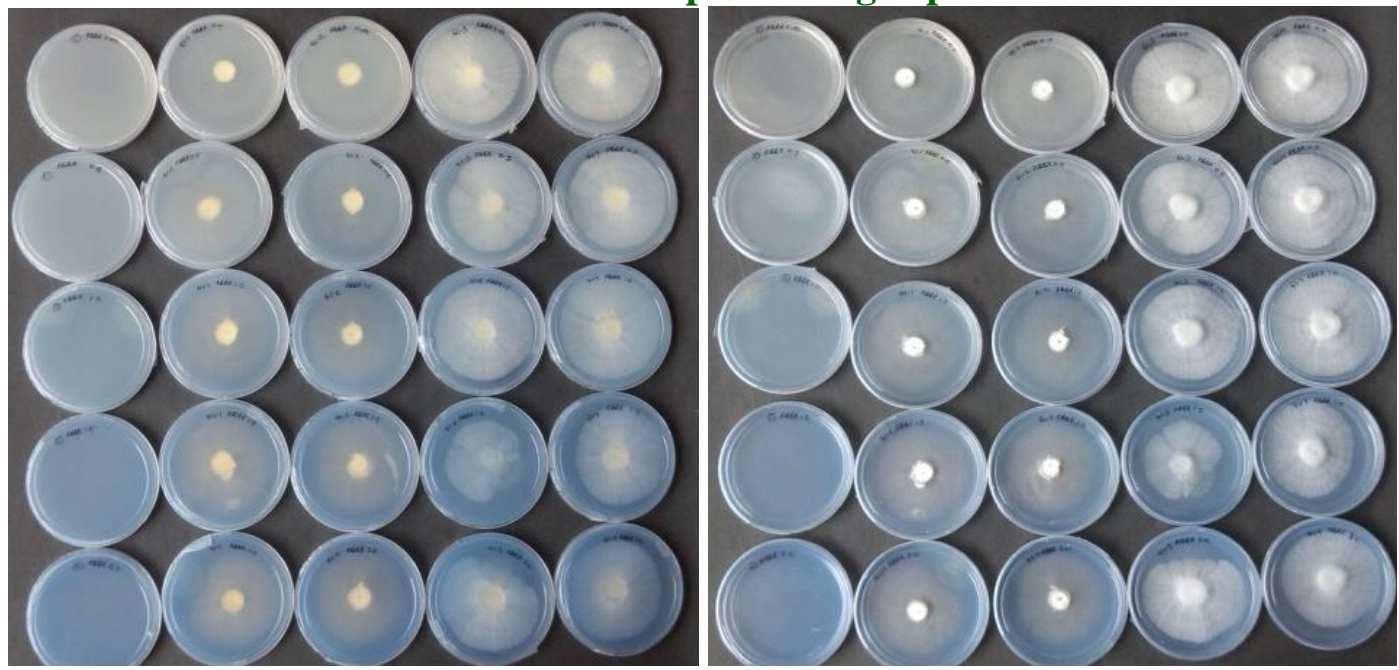

C. RBBR incorporated agar plates 
The percent guaiacol oxidation of total plate area obtained on $5^{\text {th }}$ day of incubation at 0.075 $\%$ guaiacol levels were $68.22 \%, 67.60 \%$, $40.11 \%$ and $35.56 \%$ for GL-2, GL-1, GL-3 and GL-4, respectively (Fig. 2B). At $0.020 \%$ RBBR levels, the dye decolorization was $20.08 \%, 17.52 \%, 2.31 \%$ and $1.78 \%$ for GL-2, GL-1, GL-3 and GL-4 strains, respectively on $5^{\text {th }}$ day of incubation (Fig. 2C).

The variable growth rates of $G$. lucidum strains on rice bran agar and M-LME agar medium were supported by the findings of Lester and Birkett (1999), where the fungi growth rates were affected by the composition of medium. Similarly the presence of chromogenic indicators, such as ABTS, guaiacol or recalcitrant dye (RBBR) also affected the radial growth rates due to their inhibitory effects dictated by their chemical structures (Tech et al., 2011). These results were in agreement with Eggert et al., (1996); Kalmiş et al., (2008) and Sing Ming et al., (2017) which indicated that ABTS as the more sensitive substrate as compared to guaiacol for detecting laccase activity in basidiomycetes.

In case of guaiacol, reddish brown color appeared due to the oxidative polymerization of guaiacol in the presence of extracellular fungal lignin modifying enzymes, which were started to appear with the increase in incubation period as well as fungal mycelial growth on the solid agar plates (Krishnaveni 2011). On the other hand, ABTS oxidation usually gave a color ranging from bright green to dark purple as a positive indication for laccase positive strains; however Alfarra et al., (2013) reported that peroxidase enzymes could also oxidize the ABTS in the presence of $\mathrm{H}_{2} \mathrm{O}_{2}$, which might be produced endogenously by the fungus. Field et al., (1992) and Kiiskinen et al., (2004) demonstrated that polymeric dyes and various indicator compounds such as RBBR, poly R478, guaiacol, and tannic acid, could be used for screening of white rot fungi on agar media for their ligninolytic abilities.

The higher potency index values, appearance of earlier and intense ligninolytic activity zones with lower growth inhibition rates of GL-1 and GL-2 strains than those of GL-3 and GL-4 strains were due to the variations at the genetic levels and different physiological requirements of the fungal cultures for enzyme inductions and productions (Kaal et al., 1995). Keyser et al., (1978) hypothesized that fungus required longer adaptation time to produce ligninolytic enzymes to metabolize xenobiotic compounds like guaiacol or RBBR dye. Second reason might be the inactivation of enzymes needed for the xenobiotic degradation during the incubation period (Teck et al., 2011). Another reason for reduced fungal growths on the RBBR or guaiacol media might be that fungi utilized the substrate for non-growth associated processes as reported by Lester and Birkett (1999), as well as for the production of ligninolytic enzymes to metabolize RBBR or guaiacol in the medium. The oxidation reaction rates for a particular compound could also be related to the fungal physiology under given set of conditions.

The obtained results were found to be in good agreement with the number of reports available, where chromatic changes were used as criteria for preliminary screening of ligninolytic capacities of the fungal cultures (Mtui and Masalu 2008; Barrasa et al., 2009; Phutela et al., 2013). Moreover, these strains with higher ligninolytic activities

The visual responses of ligninolytic potential were dependent on the fungal strain and the type of chromogenic compound used. Though the visual expressions of ligninolytic potentials of fungal strains were easily 
detectable at higher concentration levels of chromogenic indicators, but there was a reduction of mycelial extension rates. ABTS was found to be best suitable chromogenic indicator for qualitative screening process based on growth rate of fungi, compound oxidation rates and potency index values. These quantitative methods provides a reliable fungal ligninolytic enzyme activities for selecting efficient fungal strains which could be further exploited for the development of cost-effective production technology that would be used for efficient treatment of textile industry wastewaters and bioremediation of polluted ecosystems.

\section{Funding}

This research did not receive any specific grant from funding agencies.

Compliance with ethical standards

\section{Conflict of interest}

The authors declare that there is no conflict of interest.

\section{References}

Alfarra, H.Y., Hasali, N.H.M., and Omar, M.N., 2013. A lignolytic fungi with laccase activity isolated from Malaysian local environment for phytochemical transformation purposes. Int. Res. J. Biological Sci 2, 51-54.

Barrasa, J.M., Martinez, A.T. and Martinez, M. J., 2009. Isolation and selection of novel basidiomycetes for decolorization of recalcitrant dyes. Folia Microbiol. 54, 59-66.

Brock, P.M., Doring, H., and Bidartondo, M.I., 2009. How to know unknown fungi: the role of a herbarium. New Phytol. 181, 719-724.
Casciello, C., Tonin, F., Berini, F., Fasoli, E., Marinelli, F., Pollegioni, L., and Rosini, E., 2017. A valuable peroxidase activity from the novel species Nonomuraea gerenzanensis growing on alkali lignin. Biotechnol. Rep. 13, 49-57.

Coll, P.M., 1993. Purification and characterization of a phenoloxidase (laccase) from the lignin-degrading basidiomycetes PM1 (CECT 2971). Appl. Environ. Microbiol. 59(8), 26072613.

D' Souza, T.M., Merrit, C.S. and Reddy, C.A., 1999. Lignin-modifying enzymes of the white rot basidiomycete Ganoderma lucidum. Appl. Environ. Microbiol. 65, 5307-5313.

Da Silva Coelho-Moreira, J., Bracht, A., Da Silva de Souza, A.C., Ferreira Oliveira, R., De Sá-Nakanishi, A.B., Giatti Marques de Souza, C., and Peralta, R.M., 2013. Degradation of diuron by Phanerochaete chrysosporium: role of ligninolytic enzymes and cytochrome P450. BioMed Res. Int. Article ID 251354.

Eggert, C., Temp, U., and Erillsson, L.I., 1996. The ligninolytic system of the white rot fungus Pycnoporus cinnabarinus: Purification and characterization of the laccase. Appl. Environ. Microbiol. 62(4), 1151-1158.

Field, J.A., deJong, E., Feijoo-Costa, G., and deBont, J.A.M., 1992. Biodegradation of polycyclic aromatic hydrocarbons by new isolates of white rot fungi. Appl. Environ. Microbiol. 58, 2219-2226.

Floch, C., Alarcon-Gutierrez, E., and Criquet, S., 2007 ABTS assay of phenol oxidase activity in soil. J Microbiol Methods 71:319-324.

Janusz, G., Kucharzyk, K.H., Pawlik, A., Staszczak, M., and Paszczynski, A.J., 2013. Fungal laccase, manganese peroxidase and lignin peroxidase: gene 
expression and regulation. Enzyme Microb. Technol. 52, 1-12.

Kaal, E.E.J., Field, J.A., and Joyce, T.W., 1995. Increasing ligninolytic enzyme activities in several white rot basidiomycetes by nitrogen sufficient media. Bioresource Technol. 53:133139.

Kalmiş, E., Yaşa, I., Kalyoncu, F., Bariş, P., and Ali, K., 2008. Ligninolytic enzyme activities in mycelium of some wild and commercial mushrooms. Afr. J. Biochem. Res. 7(23), 4313-4320.

Kersten, P., and Cullen, D., 2007. Extracellular oxidative systems of the lignin-degrading Basidiomycete

Phanerochaete chrysosporium. Fungal Genet. Biol. 44, 77-87.

Keyser, P., Kirk, T.K., and Zeikus, J.G., 1978. Ligninolytic enzyme system of Phanerochaete chrysosporium: Synthesized in the absence of lignin in response to nitrogen starvation. J. Bacteriol. 135(3), 790-797.

Kiiskinen, L.L., Ratto, M., and Kruus, K., 2004. Screening for novel laccase producing microbes. J. Appl. Microbiol. 97, 640-646.

Krishnaveni, M., 2011. Characterization and decolorization of dye and textile effluent by laccase from Pleurotus florida- A white-rot fungi. Int. J. Pharma Bio. Sci. 2(1), B117-123.

Lanfermann, I., Linke, D., Nimtz, M., and Berger, R., 2015. Manganese peroxidases from Ganoderma applanatum degrade $\beta$-carotene under alkaline conditions. Appl. Biochem. Biotechnol. 175, 3800-3812.

Lee, J.S., Lim, M.O., Cho, K.Y., Cho, J.H., Chang, S.Y., and Nam, D.H. 2006. Identification of medicinal mushroom species based on nuclear large subunit rDNA sequences. J. Microbiol. 44, 2934.
Lester, J.N., and Birkett, J.W., 1999. Microbiology and chemistry for environmental scientists and engineers, $2^{\text {nd }}$ ed, E \& FN spon, New York.

López, M.J., Guisado, G., Vargas-García, M.C., Suárez-Estrella, F., and Moreno, J., 2006. Decolorization of industrial dyes by ligninolytic microorganisms isolated from composting environment. Enzyme Microb. Technol. 40(1), 42-45.

Mtui, G., and Masalu, R., 2008. Extracellular enzymes from brown rot fungus Laetiporus sulphureus isolated from mangrove forests of coastal Tanzania. Sci. Res. Essay Acad. J. 3, 154-161.

Murugesan, K., Nam, I.H., Kim, Y.M., and Chang, Y.S., 2007. Decolorization of reactive dyes by a thermostable laccase produced by Ganoderma lucidum in solid culture. Enzyme Microb Technol. 40(7), 1662-1672.

Phutela, U.G., Sahni, N., Sooch, S.S., and Soni, R., 2013. Preliminary screening of isolated fungi for their lignocellulolytic potential. J. Res. 48(3\&4), 195-200.

Rivera-Hoyos, C.M., Morales-Álvarez, E.D., Poveda-Cuevas, S.A., Reyes-Guzmán, E.A., Poutou-Piñales, R.A., ReyesMontaño, E.A., Pedroza-Rodríguez, A.M., Rodríguez-Vázquez, R., and Cardozo-Bernel, Á.M. 2015. Computational analysis and low-scale constitutive expression of laccases synthetic genes GILCC1 from Ganoderma lucidum and POXA $1 B$ from Pleurotus ostreatus in Pichia pastoris. PLoS ONE 10(1): e0116524. https://doi.org/10.1371/journal.pone.011 6524

Rodríguez Couto, S., 2009. Dye removal by immobilised fungi. Biotechnol. Adv. 27, 227-235.

Sanchez, C., 2009. Lignocellulosic residue: biodegradation and bioconversion by fungi. Biotechnol. Adv. 27(2), 185-194. 
Shrestha, P., Joshi, B., Joshi, J., Malla, R., and Sreerama, 2016. Isolation and Physicochemical characterization of laccase from Ganoderma lucidumCDBT1 isolated from its native habitat in Nepal. Biomed. Res. Int 3238909, doi: 10.1155/2016/3238909

Sin Ming, Goh, Mun Yee, Chan., and Lisa Gaik Ai, Ong. 2017. Degradation potential of basidiomycetes Trametes ljubarskyi on reactive violet 5 (RV 5) using urea as optimum nitrogen source. Biotechnol. Biotechnol. Equip. 31(4), 743-748.
Teck, N.A., Gek, C.N., and Adeline, S.M.C., 2011. A quantitative method for fungal ligninolytic enzyme screening studies. Asia-Pacific J. Chemical Eng. 6, 589595.

Uhlig, H., 1998. Industrial enzymes and their applications. John Wiley \& Sons, Inc, New York.

Wunch, K.G., Feibelman, T., and Bennett, J.W. 1997. Screening for fungi capable of removing Benzo[ $\alpha]$ pyrene in culture. Appl. Microbiol. Biotechnol. 47, 620624.

\section{How to cite this article:}

Harsimran Kaur, S. Kapoor and Shivani Sharma. 2018. An Efficient Method for Qualitative Screening of Ligninolytic Enzyme Potential of Ganoderma lucidum. Int.J.Curr.Microbiol.App.Sci. 7(08): 2442-2459. doi: https://doi.org/10.20546/ijcmas.2018.708.247 